\title{
Outcome and Clinical Spectrum of Post-streptococcal Glomerulonephritis in Children in Developing Countries
}

\author{
Saber A.M. El-Sayed*, Yasser F. Ali ${ }^{* *}$, Mostafa M. Ahmady, Salah F. Alsayed ${ }^{* * *}$ and Ahmed M. Baraka ${ }^{* * * *}$ \\ *Department of Pediatrics, National Research Center, Cairo, Egypt \\ ** Department of Pediatrics , Faculty of Medicine, Zagazig University, Egypt \\ Department of internal medicine Faculty of Medicine, Zagazig University, Egypt \\ Clinical \& chemical pathology, Faculty of Medicine, Zagazig University, Egypt \\ *Corresponding author's email: saber_196215 [AT] yahoo.com
}

\begin{abstract}
---
Background: Post streptococcal glomerulonephritis with crescentic glomerulonephritis is an uncommon outcome in children. This study was done to evaluate the clinical spectrum and outcome in children with crescentic glomerulonephritis following acute post-streptococal glomerulonephritis. The diagnosis of underlying renal disease was based on various criteria, including the clinical picture, serology and histopathology. The patients received treatment in the form of intravenous methyl prednisolone, oral steroid treatment, and oral cyclophosphamide .

Objective: to evaluate the clinical spectrum and outcome of the pediatric patients with post-streptococal crescentic glomerulonephritis admitted or referred in Zagazig general hospital in nephrology unit.

Study design: The study included ( 20 ) children patients with biopsy proven crescentic golmerulonephritis following APSGN admitted or referred from other hospitals to the nephrology unit in Zagazig general hospital between Marsh 2010 to May 2016 These patients were subjected to detailed clinical and biochemical examinations including urine analysis ,U\&E ,serum albumin, ASOT, anti- DNase-B test, complements ( C3 and C4), ANA, ANCAs ,anti- DNA antibodies; anti-(GBM) antibodies. The diagnosis of underlying renal disease was based on various criteria, including the clinical picture, serology and histopathology by light immunofluorescence and electron microscopy and all patients were taken immunosuppressive treatment.

Results: 20 patients with poststreptococcal crescentic glomerulonephritis (12 males and 8 females). The mean age of patients at the time of presentation was (7.5) years with range of 5 to 12 years. All were having gross hematuria ,progressive rise of serum creatinine, mean creatinine was 571.5 umol/l with range of (413umol/- 822umol/1), low complement C3, 16 patients were having hypertension (80\%),10 patients (50\%) had nephrotic range of proteinuria and remaining were having moderate range. Renal biopsy which revealed more than $50 \%$ crescents in all biopsies with mean of $62.5 \%$ and ranging between 50-90\%. 4 patients had fibrocellular crescents (20\%) and 16 had cellular crescents (80\%). the mean follow up duration in months was 25 mo ranging between 22-28 months after immunosuppression,16 patients regained their normal kidney functions (80\%) with mean creatinine 47 umol/l ranging between (40-68) P-value $<0.001 * .4$ patients (20\%) had residual renal impairment, these 4 patients had fibro cellular crescents in renal biopsy. 8 patients regained their normal blood pressure at last follow up (80\%) $P$-value $<0.001 * *$.

Conclusion: the overall outcome of 20 patients with post streptococcal crescentic glomerulonephritis was accepted \& excellent, 16 patients out of 20 (80\%) regained their normal kidney functions. Due to the limited number of our patients, large multi-center study is needed to prove this result.
\end{abstract}

Keyword--- Crescentic glomerulonephritis, post streptococcal glomerulo-nephritis chronic kidney diseases proteinuria, rapidly progressive glomerulonephritis, immune-complex disease

\section{INTRODUCTION}

Acute post-streptococal glomerulonephritis in children is most commonly caused by group A beta-heamolytic Streptococcus organism, also other strain of Streptococci can be the cause of affection like Streptococcus pneumonia (1) , Lancefield group C \& G Streptococci which known as Streptococcal zooepidermicus (2) nephritogenic strains . Acute 
post-Streptococcal glomerulo-nephritis affect annually more than five hundred thousands patients $98 \%$ in developing countries, leading to death of more than 5 thousands children (3).

Nephritogenic strains subdivided into strains associated with pyoderma and strains cause pharyngitis $(24,25)$. This is a fact that pyoderma-associated strains sometimes cause pharyngitis at the same time, by transfer of bacteria from the skin to the oropharynx (19).

Rapidly progressive glomerulonephritis (RPGN one of rare childhood renal diseases characterized by presence of excessive crescents in the glomeruli during histopathological renal biopsy resulting in crescentic glomerulonephritis with progressive decrease in renal functions taking days or weeks (4). Kidney biopsy for all patients by highly expert histopathologist done by light and immunofluorescence microscope . The histopathologic evaluation include the number of crescentic glomeruli ,types of crescents which were cellular, fibrocellular, fibrous. Presence of cells filling small part or all the Bowman's capsule were defined as cellular crescents but when the lesion similar to cellular crescents with variable amount of fibrillar material defined as fibrocellular, but if the lesion within the Bowman's capsule composed predominantly of fibrous tissue defined as fibrous crescents (10).

Risdon A et .al , (8) series study group of 30 children with renal affection only two child had acute post streptococcal glomerulonephritis as the first diagnosis, Another large series study of children with crescentic glomerulonephritis by South West Pediatric Nephrology (5) reported group of 50 children with CGN , only 6 of them due to acute post streptococcal glomerulonephritis . Systemic lupus erythematous and Henoch-Schönlein purpura lead to vasculitides these together most common cause of crescentic glomerulonephritis. Morris et.al. (5) reported that acute post streptococcal glomerulonephritis the leading cause of of crescentic or rapidly progressive glomerulonephritis, In this study from New Zealand, they examined clinical pictures and management of acute post streptococcal glomerulonephritis in 27 patients

In New Zealand they reported that urinary abnormalities in the patients with crescentic glomerulonephritis and 11 patients need acute dialysis after 3 years of follow up under treatment of immunosuppressive therapy which were un benefit in that children .

The purpose and the aim of this study to evaluate outcome and Clinical spectrum of post-streptococcal rapidly progressively glomerulonephritis in children referred or admitted to our unit .

\section{PATIENTS \& METHOD}

Our study included all children suffering from acute post-streptococcal glomerulonephritis with complication of crescentic glomerulonephritis following up by admission or referral from any hospitals to the nephrology unit of Zagazig general and Health Insurance hospitals in Sharkia in the period between Marsh 2010 to May 2016. The criteria for selection of the patients were: 1-Those with clinical and laboratory criteria of rapidly progressive glomerolunephritis that proven by renal biopsy to be accurate diagnosed crescenteric glomerulonephritis . 2- They have criteria of poststreptococcal infection. Acute post-streptococcal glomerulonephritis to be diagnosed have criteria which were:- 1Streptococcal titers elevated, 2- C3 complement decreased, 3- No history of chronic renal diseases . When the clinical and laboratory data of the patients matched with acute post-sreptococcal glomerulonephritis the diagnosis was made especially if prognoses of the symptoms were increased. Presence of numerous epithelial crescents filling the Bowman's capsules of more than $50 \%$ of glomerular biopsy defined as crescentic glomerulonephritis.

\section{Our studying patients were underwent to :-}

1-1-Ethical approval was obtained from the local research ethics committee of the nephrology unit of Zagazig general and Health Insurance hospitals in Sharkia, and parents of all children gave an informed written consent prior to the study. Clinical and laboratory study for all patients in the form of age and sex of every one at presentation , history of preceding upper respiratory tract infections or skin infection, gross hematuria, periorbital edema or generalized, oliguria , proteinuria , hypertension, microscopic urine analysis for proteins, RBCs count and casts, serum albumin and creatinine and ratio of urine protein/creatinine. 2- Serological study for all patients which were Anti-Streptolysin O titre (ASO) titre, anti- DNase-B test, serum C3 and C4, antinuclear antibodies, anti-double-stranded DNA antibodies; antiglomerular basement membrane antibodies, anti-neutrophilic cytoplasmic antibodies . 3- Histopathological renal biopsy which were indicated in patients with : rapid increased serum creatinine level more than upper limits of the normal within 5-15 days of presentation of clinical symptoms, anuria with ranal failure, the patient underwent mixed type of nephrotic nephritis syndrome, 2-3 weeks delaying in recovery of renal failure after onset of nephritis, more than 15 days persistence of gross heamaturia. The biopsy needed might be reported by clever and expert histo-pathologists to be studied by light, immune-fluorescence and electronic microscopy evaluating the total glomeruli numbers with crescents and their types if cellular, fibrocellular and fibrous according to definitions and classifications of renal diseases by Sobin $\mathrm{LH}$ et al. (6) . Presence of +3 or more than protein on dipstick test or urine protein creatinine ratio more than 200 $\mathrm{mg} / \mathrm{mmol}$ is defined as nephrotic range proteinuria . 4- The following regimen were used with the patients in our study they were managed by taking methyl-prednisolone intravenous in the form of $600 \mathrm{mg} / \mathrm{m} 2$ for 6 doses then followed by 
cyclophosphamide $2.5 \mathrm{mg} / \mathrm{kg} /$ day oral for at least 2 months and daily prednisolone for one month followed by alternative dose foe one month then start weaning . 12 patients $(60 \%)$ from the twenty due to oligo /anuria and hypervolemia needed acute dialysis 5- All patients underwent to follow up plan which were done by 1- clinical evaluation every month for gross hematuria ,anuria or oliguria ,hypertension, edema of lower limbs . 2- Laboratory evaluation by urine analysis and urine dipstick for proteins or RBCs, CBC ( total and differential ) leukocyte counts, serum creatinine level ,serum albumin level and C3\&C4 every 3 months.

\section{RESULTS}

Our study data found twenty-six patients suffering from rapidly progressive glomerulonephritis with different etiological causes. Excluding six child from the study. Also the two patients not accurate diagnosed crescentic glomerulo-nephritis in spite of all clinical and laboratory results of post- streptococcal glomerulonephritis but the parents refused the renal biopsy to be done. The etiological criteria of post streptococcal had not found in the other four patients, while renal biopsy for two girl patients of them aged 18 months admitted in pediatric intensive care unit found membranoprolifrative glomerulonephritis type-1 with more than $75 \%$ fibrous crescents with renal failure exposed to continuous veno-venous hemodialysis without improvement the prognosis then was bad finely they died. The remaining two male child aged 2 , 2.5 years respectively presented with edema which is generalized affect all the body, excessive proteinuria, sever rise of blood pressure, impaired renal functions with rapid elevated serum creatinine and the histopathologic biopsy of the kidney revealed $100 \%$ cellular crescents as (membranoprolifrative glomerulonephritis type-1).Their kidney functions deteriorated in spite of received immunosuppressive therapy in the form of methyle-prednisolone, intravenous cyclophosphamide and rituximab ( anti-CD20 anti body ), but the managements failed and they regularly needed dialysis support and referred to Central Auditory Processing Disorders. Laboratory and serological results of the patients at $\underline{1^{\text {st }}}$. presentation and their descriptive analysis as shown in table (1) and table (2) respectively:

- All the patients evaluated in our study Were diagnosed post streptococcal crescent glomerulonephritis according to clinical symptoms, laboratory evidence of renal infection by streptococci and renal biopsy results .

- The twenty patients of the study twelve (60\%) of them were males and the remaining eight were females (40\%). The mean age of them at time of presentation was 7.5 years with range of 5 to 12 years.

- All the twenty patients evaluated in our study were having gross hematuria, sever rise of serum creatinine . Sixteen patients $(80 \%)$ of them were had hypertension, ten from the sixteen were males $(63 \%)$ and $(37 \%)$ six from the sixteen were females the remaining last four normotensive patients (20\%) 2 of the last four were males and the other 2 females. The mean duration of symptoms before performing biopsy

- The mean duration of symptomps befor made the biopsy was 20 days with range 15-30 days. The mean of rising creatinine was 571.5 with range of ( 413-822). 10 out of $20(50 \%)$ were had nephrotic range of proteinuria and the other 10 ( $50 \%)$ were had moderate range of proteinuria. The mean serum albumin for all patients ( the 20 patients ) was 20 at presentation. The mean serum albumin was 19.7 at presentation. Four of the patients with nephrotic range of proteinuria by kidney biopsy they had fibrocellular crescents and also the other six patients had cellular crescents.

- Preceding streptococcal infection criteria for all patients, high ASO titre (mean was 733.1 and range of 4601410) .

- $\quad$ All the (20) patients had low C3 (100\%). No patient from them had $\downarrow$ C4 complement. 16 patients from the 20 $(80 \%)$ had history of UTRI, 2 from the 20 had history of preceding skin infection (10\%), and the last 2 patients had no evidence of clinical infection before their presentation (10\%).Anti-DNase-B was positive for 18 patients and unfortunately result was not found for the $20^{\text {th }}$ patient. None of the 20 patients had positive antinuclear antibodies ANA, anti neutrophil cyotplasmic antibodies pANCA or cANCA or anti glomerular basement membrane test. Hepatitis B surface antigen serology was negative for all 20 patients.

\section{Results of the last follow up showed in table (3) and table (4) respectively.}

The patients in our study were managed by taking methyl-prednisolone intravenous in the form of $600 \mathrm{mg} / \mathrm{m} 2$ for $6 \mathrm{doses}$ then followed by cyclophosphamide $2.5 \mathrm{mg} / \mathrm{kg} /$ day oral for at least 2 months and daily prednisolone for one month followed by alternative dose foe one month then start weaning . 12 patients (60\%) from the twenty due to oligo /anuria and hypervolemia needed acute dialysis . 25 months was the mean follow up duration with a range from 22 to 30 months . The patients whose regained their kidney functions and became normal were 16 patients $(80 \%)$ with mean creatinine level $56 \mathrm{mmol} / 1$ with a range from 40 upto $64 \mathrm{mmol}$ so this mean the improvements were significant, P-value less than 
$0.001 * *$. But the remaining 4 patients had kidney functions impairment 2 patients from the 4 with serum creatinine 120 mmol /l inspite of following up for 30 months with their glomerular filtration rate $40 \mathrm{ml} / \mathrm{min}$. these 2 patients needed double antihypertensive therapy due to sever rise their blood pressure to be controlled. the subnehprotic range of proteinuria on antiprotein-uric agent, the 4 patients $(20 \%)$ were had nephrotic range of proteinuria P-value less than $0.001 * *$. These 2 patients out from the 4 patients referred after appear of symptoms by 21 days reported fibro-cellular crescents in the histopathologic biopsy needed antihypertensive therapy due to hypertension . The four patients with impaired renal functions his serum creatinine level was $71.5 \mathrm{mmol} / \mathrm{l}$ and his glomerular filtration rate was $66 \mathrm{ml} / \mathrm{min}$. underwent regular follow up. The serum albumen became near normal in 16 patients about $36 \mathrm{~g} / \mathrm{l}$ with range $32 \mathrm{~g}$ to $40 \mathrm{~g}$, $\mathrm{P}$-value less than $0.001^{* *}$. But the other four patients their serum albumen was $30 \mathrm{~g} / \mathrm{l}$. Normal blood pressure returned in the 16 patients $\mathrm{P}$-value less than $0.001 * *$.

\section{Results of the renal biopsy as shown in figure (1):}

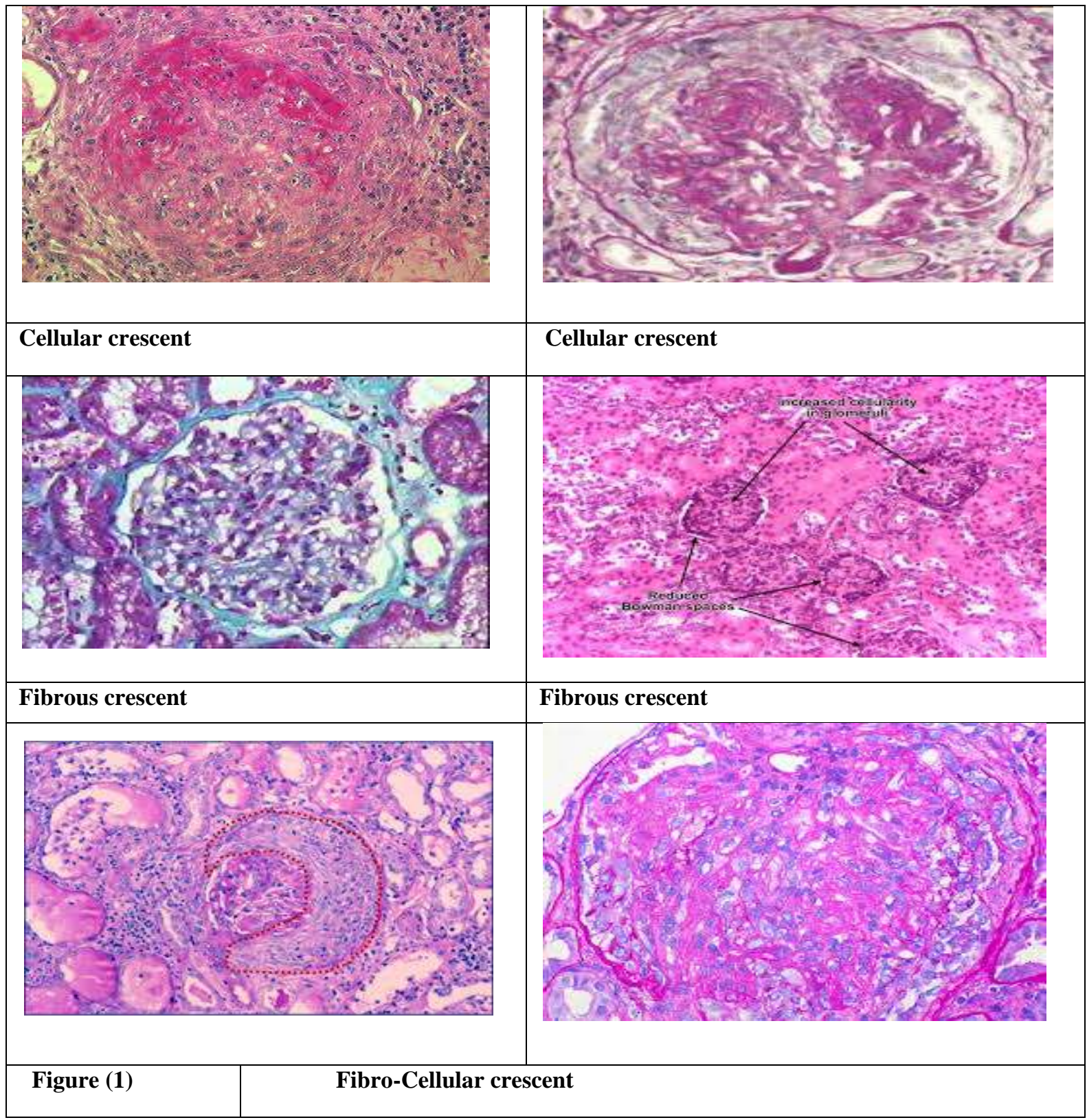

All the 20 patients in our study underwent to kidney biopsy which revealed more than $50 \%$ crescents in all biopsies with mean of $63 \%$ and ranging between $50-90 \%$. 4 patients had fibrocellular crscents(20\%) and 16 patients had cellular crescents $(80 \%)$.No patient had fibrous crescents. In the patients of our study, the glomeruli show diffuse proliferation of mesangial and endothelial cells with neutrophils infiltrate and obliteration of the capillary lumina. The tubules in most of the cases show ATN - ike changes with regenerative changes and casts inside the Lumina. The interistium shows edema, 
mild fibrosis and focal lympho-plasma cells infiltrate. The blood vessels are unremarkable. IF showed diffuse coarse granular reaction along capillary loops and mesangium for IgG and C3 or C3 alone. EM shows numerous sub-epithelial humps like deposits. All the histopathological biopsy of 20 patients glomeruli of the study shown diffuse proliferation crescentic cellular, fibrocellular or fibrous in the glomeruli taken number of glomeruli different in every patient according to the severity of the disease the percentage of crescents range from $50 \%$ to $85 \%$.

Table (1) : Laboratory and serological results of the patients at $1^{\text {st }}$. presentation

\begin{tabular}{|c|c|c|c|c|c|c|c|c|c|c|c|}
\hline & $\begin{array}{l}\text { age } \\
\text { in } y .\end{array}$ & sex & $\begin{array}{l}\text { BP at } \\
\text { presen- } \\
\text { tation }\end{array}$ & $\begin{array}{l}\text { Time to biopsy } \\
\text { from } \\
\text { admission }\end{array}$ & $\begin{array}{l}\text { presenting with } \\
\text { nephrotic proteinura }\end{array}$ & $\begin{array}{l}\text { peak(low) } \\
\text { serum } \\
\text { albumen }\end{array}$ & \begin{tabular}{l}
\multicolumn{1}{c}{ Peak } \\
(high) serum \\
creatinine
\end{tabular} & ASOT & C3 & $\begin{array}{l}\text { Anti- } \\
\text { DNAe B }\end{array}$ & $\begin{array}{l}\text { ANA,Anti DNA, } \\
\text { pANCA cANCA, } \\
\text { Anti GBM } \\
\text {,Hepatitis B, } \\
\text { serology }\end{array}$ \\
\hline 1 & 10 & $\mathbf{M}$ & high & 17 & $\mathbf{Y}$ & 23 & 758 & 763 & Low & + & $\mathbf{N}$ \\
\hline 2 & 8 & $\mathbf{M}$ & high & 16 & $\mathbf{N}$ & 21 & 762 & 552 & Low & + & $\mathbf{N}$ \\
\hline 3 & 11 & $\mathbf{F}$ & high & 20 & $\mathbf{N}$ & 25 & 738 & 1016 & Low & + & $\mathbf{N}$ \\
\hline 4 & 5 & $\mathbf{F}$ & low & 17 & $\mathbf{N}$ & 24 & 512 & 672 & LOW & + & $\mathbf{N}$ \\
\hline 5 & 12 & M & high & 30 & $\mathbf{Y}$ & 19 & 522 & 1410 & L0W & + & $\mathbf{N}$ \\
\hline 6 & 7 & $\mathbf{M}$ & high & 18 & $\mathbf{Y}$ & 17 & 594 & 650 & LoW & + & $\mathbf{N}$ \\
\hline 7 & 10 & $\mathbf{M}$ & low & 27 & $\mathbf{Y}$ & 16 & 614 & 660 & L0W & + & $\mathbf{N}$ \\
\hline 8 & 7 & $\mathbf{F}$ & high & 17 & $\mathbf{Y}$ & 15 & 503 & 550 & LoW & + & $\mathbf{N}$ \\
\hline 9 & 6 & $\mathbf{M}$ & high & 17 & $\mathbf{N}$ & 21 & 423 & 1020 & LOW & + & $\mathbf{N}$ \\
\hline 10 & 8 & $\mathbf{F}$ & high & 21 & $\mathbf{N}$ & 23 & 458 & 640 & L0W & NOT & $\mathbf{N}$ \\
\hline 11 & 9 & $\mathbf{M}$ & high & 20 & $\mathbf{Y}$ & 18 & 423 & 650 & LOW & + & $\mathbf{N}$ \\
\hline 12 & 8 & $\mathbf{M}$ & low & 20 & $\mathbf{N}$ & 21 & 642 & 1400 & LOW & + & $\mathbf{N}$ \\
\hline 13 & 11 & $\mathbf{F}$ & high & 23 & $\mathbf{N}$ & 18 & 413 & 730 & L0W & + & $\mathbf{N}$ \\
\hline 14 & 6 & $\mathbf{F}$ & low & 18 & $\mathbf{N}$ & 20 & 623 & 460 & LOW & + & $\mathbf{N}$ \\
\hline 15 & 11 & $\mathbf{M}$ & high & 20 & $\mathbf{Y}$ & 16 & 453 & 550 & LOW & + & $\mathbf{N}$ \\
\hline 16 & 7 & $\mathbf{M}$ & high & 16 & $\mathbf{Y}$ & 15 & 676 & 550 & LoW & NOT & $\mathbf{N}$ \\
\hline 17 & 10 & $\mathbf{M}$ & high & 23 & $\mathbf{Y}$ & 15 & 549 & 530 & LOW & + & $\mathbf{N}$ \\
\hline 18 & 7 & $\mathbf{F}$ & high & 18 & $\mathbf{Y}$ & 16 & 509 & 565 & L0W & + & $\mathbf{N}$ \\
\hline 19 & 9 & $\mathbf{M}$ & high & 23 & $\mathbf{N}$ & 24 & 822 & 775 & LOW & + & $\mathbf{N}$ \\
\hline 20 & 8 & $\mathbf{F}$ & high & 19 & $\mathbf{N}$ & 26 & 608 & 520 & LOW & + & $\mathbf{N}$ \\
\hline
\end{tabular}

$\mathrm{BP}=$ blood pressure. $\mathrm{s}$. albumin=serum albumen $\mathrm{ASOT}=$ anti streptolysin o titer.

$\mathrm{C} 3=$ complement $\mathrm{C} 3 . \mathrm{ANA}=$ anti neuclear antibody $\mathrm{ANCA}=$ anti neutrophil cytoplasmic antibody. Anti GBM=anti glomerular basement membrane antibody. 
Table (2): Analysis of the outcome results at 1st. presentation

\begin{tabular}{|c|c|c|}
\hline \multicolumn{2}{|c|}{ variable } & No \\
\hline \multicolumn{2}{|c|}{$\operatorname{Age}(\mathrm{y})$} & $7.5 \pm 2.6(5-12)$ \\
\hline \multirow{2}{*}{ Sex } & Male & $12(60 \%)$ \\
\hline & female & $08(40 \%)$ \\
\hline \multicolumn{2}{|c|}{ Time to biopsy from admission (days) } & $20 \pm 5(15-30)$ \\
\hline \multicolumn{2}{|c|}{$\mathrm{BP}$ (high) at presentation } & $16(80 \%)$ \\
\hline \multicolumn{2}{|c|}{ peak(high) serum creatinine } & $571.5 \pm 102(413-822)$ \\
\hline \multicolumn{2}{|c|}{ peak(low) s .albumen } & $19.7 \pm 5.9(15-26)$ \\
\hline \multicolumn{2}{|c|}{ presenting with nephrotic proteinuria } & $10(50 \%)$ \\
\hline \multicolumn{2}{|c|}{ ASOT } & $733.1 \pm 121(460-1410)$ \\
\hline \multicolumn{2}{|c|}{ low $\mathrm{C} 3$ at presentation } & $20(100 \%)$ \\
\hline
\end{tabular}

Table (3): Laboratory and serological results of the patients at last follow-up

\begin{tabular}{|c|c|c|c|}
\hline & $\begin{array}{l}\text { at } 1^{\text {st }} \text {. } \\
\text { presentation }\end{array}$ & $\begin{array}{l}\text { At last } \\
\text { follow up }\end{array}$ & P-value \\
\hline s.creatinine & $\frac{571.5 \pm 102}{(413-822)}$ & $54.7 \pm 18.2$ & $\begin{array}{l}\leq \\
0.001 * *\end{array}$ \\
\hline s.albumin & $\frac{19.7 \pm 5.9}{(15-26)}$ & $34.3 \pm 3.4$ & $\begin{array}{l}\leq \\
0.001 * *\end{array}$ \\
\hline B.P (high) & $16(80 \%)$ & $4(20 \%)$ & $\begin{array}{l}< \\
0.001^{++}\end{array}$ \\
\hline proteinuria & $10(50 \%)$ & $2(10 \%)$ & $\begin{array}{l}< \\
0.001^{++}\end{array}$ \\
\hline
\end{tabular}


Table (4): Laboratory and serological results of the patients at last follow up.

\begin{tabular}{|c|c|c|c|c|c|c|c|}
\hline $\begin{array}{l}\text { No. } \\
\text { patient }\end{array}$ & $\begin{array}{l}\text { duration in months } \\
\text { follow up }\end{array}$ & last BP & $\begin{array}{l}\text { Last ser. } \\
\text { albumen }\end{array}$ & $\begin{array}{l}\text { Last ser. } \\
\text { creatinine }\end{array}$ & $\begin{array}{l}\text { last urine } \\
\text { protein }\end{array}$ & $\begin{array}{l}\text { Acute } \\
\text { dialysis }\end{array}$ & outcome \\
\hline 1 & 26 & $\mathbf{N}$ & 30 & 120 & Nil & Yes & \\
\hline 2 & 28 & HIN & 32 & 53 & Trace & Yes & On anti-hypertensive (amlodipine) \\
\hline 3 & 24 & $\mathbf{N}$ & 37 & 40 & Trace & No & \\
\hline 4 & 25 & $\mathbf{N}$ & 36 & 53 & Nil & Yes & $\begin{array}{l}\text { Stage three CKD -regular - follow up } \\
\text { in CKD clinic }\end{array}$ \\
\hline 5 & 24 & $\mathbf{N}$ & 35 & 53 & Trace & No & \\
\hline 6 & 23 & HIN & 30 & 120 & Trace & Yes & On anti-hypertensive (amlodipine) \\
\hline 7 & 22 & $\mathbf{N}$ & 40 & 41 & + & No & \\
\hline 8 & 26 & $\mathbf{N}$ & 34 & 49 & Trace & Yes & $\begin{array}{l}\text { Stage three CKD -regular- follow up in } \\
\text { CKD clinic }\end{array}$ \\
\hline 9 & 24 & $\mathbf{N}$ & 35 & 52 & Nil & No & \\
\hline 10 & 24 & HIN & 30 & 50 & Trace & Yes & On anti-hypertensive (ACEi) \\
\hline 11 & 24 & $\mathbf{N}$ & 36 & 49 & Nil & No & \\
\hline 12 & 23 & $\mathbf{N}$ & 37 & 48 & Trace & Yes & $\begin{array}{l}\text { Stage two CKD -regular - follow up in } \\
\text { CKD clinic }\end{array}$ \\
\hline 13 & 26 & $\mathbf{N}$ & 36 & 42 & Trace & No & \\
\hline 14 & 27 & $\mathbf{N}$ & 38 & 52 & + & Yes & On anti-hypertensive (ACEi) \\
\hline 15 & 26 & $\mathbf{N}$ & 30 & 55 & Trace & No & \\
\hline 16 & 28 & $\mathbf{N}$ & 36 & 55 & Nil & Yes & $\begin{array}{l}\text { Stage two CKD -regular - follow up in } \\
\text { CKD clinic }\end{array}$ \\
\hline 17 & 25 & $\mathbf{N}$ & 37 & 49 & Trace & No & \\
\hline 18 & 26 & HIN & 34 & 53 & Trace & Yes & On anti-hypertensive (ACEi) \\
\hline 19 & 27 & $\mathbf{N}$ & 35 & 46 & Nil & Yes & \\
\hline 20 & 24 & $\mathbf{N}$ & 38 & 61 & Trace & Yes & \\
\hline
\end{tabular}

\section{DISCUSSION}

This study is to evaluate the clinical spectrum and outcome of the pediatric patients with post-streptococal crescentic glomerulonephritis admitted or referred in Zagazig general hospital in nephrology unit. The study found twenty six patients with crescentic glomerulonephritis according to different causes 20 patients out of them with biopsy proven crescentic golmerulonephritis following APSGN admitted or referred from other hospitals to the nephrology unit in Zagazig general hospital between Marsh 2010 to May 2016 These patients were subjected to detailed clinical and biochemical examinations . El-Agroudy et.al. (13) recorded that post streptococcal glomerulonephritis between Egyptian 
children was higher than other area the reason supposed to the endemic prevalence of streptococcal infections . (14) Sharma et. al. they recorded in their study the most common cause of crescentic glomerulo-nephritis was due to immune complex crescentic glomerulo-nephritis with a percentage of 86,4\%. Steele et. al. (16) in their studied of 56 patients with glomerular affections 2 out of them had post streptococcal crescentic glomerulonephritis. by Sobin et al. (6) study had be done in multi centers they found $12 \%$ of patients with crescentic glomerulonephritis due to post streptococcal infections like our countries .

Our study result recorded that low complement C3 level of all 20 patients in spite of some studies in New Zealand by Morris et.al. (5) that found 4 patients out of 11 patients had normal complements C3 level also Herdson et. al. (18) had normal complements C3 level in their study. All the twenty patients had low C3 (100\%). No patient from them had decreased C4 complement. 16 patients from the $20(80 \%)$ had history of UTRI, 2 from the 20 had history of preceding skin infection (10\%), and the last 2 patients had no evidence of clinical infection before their presentation (10\%).AntiDNase-B was positive for 18 patients and unfortunately result was not found for the $20^{\text {th }}$ patient. None of the 20 patients had positive antinuclear antibodies ANA, anti-neutrophil cytoplasmic antibodies pANCA or cANCA or anti glomerular basement membrane (anti GBM )test. Hepatitis B surface antigen serology was negative for all 20 patients. The patients in our study were managed by taking methyl-prednisolone intravenous in the form of $600 \mathrm{mg} / \mathrm{m} 2$ for $6 \mathrm{doses}$ then followed by cyclophosphamide $2.5 \mathrm{mg} / \mathrm{kg}$ /day oral for at least 2 months and daily prednisolone for one month followed by alternative dose foe one month then start weaning . 12 patients $(60 \%)$ from the twenty due to oligo /anuria and hypervolemia needed acute dialysis . 25 months was the mean follow up duration with a range from 22 to 30 months so in simple acute proliferative glomerulonephritis immunosuppressive treatment is not indicated best recommended in improveing outcome of patients with crescentic glomerulo-nephritis .The prognosis is good except in cases associated with severe kidney failure and crescentic glomerulonephritis the prognosis is bad Fuentes et. al. (20) recommended to give immunosuppressive therapy together with any other therapy . Hebert et.al.(21) recorded post pharyngitis outcome patient with rapidly progressive glomerulonephritis associated with nephrotic range proteinuria proven by serology and biopsy treated with antihypertensive drug and steroids therapy lead to improvement of kidney functions and proteinuria . Murphy et. al. (17) found no difference in treatment of 10 patients with crescentic glomerulonephritis between given (prednisone, cyclophosph-amide, azathioprine , dipyridamole , and anticoagulant) and those treated with supportive care in their 10 patients study. Morris et. al .(5) recently study of twenty seven patients eleven patients of them had more than $50 \%$ crescents proven by renal biopsy treated with immunosuppressive therapy but no benefit . The most importance outcome from our studying on twenty patients of acute post-streptococcal creascentic glomerulonephritis noted that the prognoses is more accepted and better in cases of creascentic post-streptococcal glomerulonephritis than other causes of creascentic glomerulonephritis . A sixteen patients ( $80 \%$ ) of all studying patients their renal functions became normal with a result of mean creatinine level were $56 \mathrm{mmol} / 1$ with a range from 40 upto 64 mmol P-value less than $0.001 * *$. And the blood pressure for them became normal which were recorded at the last visit during follow up P-value less than $0.001^{* *}$. But the other four patients from the twenty (20\%) their renal functions were impaired. 2 patients from the 4 with serum creatinine $120 \mathrm{mmol} / \mathrm{l}$ inspite of following up for 30 months with their glomerular filtration rate $40 \mathrm{ml} / \mathrm{min}$. these 2 patients needed double antihypertensive therapy due to sever rise their blood pressure to be controlled . the subnehprotic range of proteinuria +1 urine dipstick on antiprotein-uric agent, the 4 patients $(20 \%)$ were had nephrotic range of proteinuria $\mathrm{P}$-value less than $0.001^{* *}$. These 2 patients out from the 4 patients referred after appear of symptoms by 21 days reported fibro-cellular crescents in the histopathologic biopsy needed antihypertensive therapy due to hypertension. The four patients with impaired renal functions his serum creatinine level was $71.5 \mathrm{mmol} / \mathrm{l}$ and his glomerular filtration rate was $66 \mathrm{ml} / \mathrm{min}$ ( stage $2 \mathrm{CKD}$ ). Under-went regular follow up . The serum albumen became near normal in 16 patients about $36 \mathrm{~g} / \mathrm{l}$ with range $32 \mathrm{~g}$ to $40 \mathrm{~g}$, P-value less than $0.001^{* *}$. But the other four patients their serum albumen was $30 \mathrm{~g} / 1$. Blood pressure became normal in the 16 patients P-value less than $0.001 * *$.

About $75 \%$ of the glomeruli had cellular crescents during histopathological study. Sobin et.al ( 6 ) recorded that 5 patients with acute pot streptococcal glomerulonephritis their glomerular filtration rate were normal in the comparison of their study for forty two patients with creascentic glomeruli of other etiology twenty three patients out of them had prognoses to end stage renal diseases . Vasudev et. al. (15) recorded that the prognosis is bad and poor in all cases of crescentic glomerulonephritis either post streptococcal crescentic glomerulonephritis or other etiology of crescentic glomerulonephritis. Sabry et. al. (22) they recorded that the relation between the percentage of glomeruli with crescentic affections and progression to ESRF was positive and confirmed that the less chance of recovery of kidney functions with more excessive formation of crescents. And the poor prognosis of post streptococcal crescentic glomerulonephritis infected patients especially if the nephrotic range proteinuria or hypertension was persist Risdon et.al.( 8 ). El-Agroudy et.al.( 13 ) they recorded that the renal function affected by the number of fibrous crescent at last follow up . Kerr et. al.( 23 ) they demonstrated that the best positive response to immunosuppressive therapy and anticoagulants in cases with acute cellular crescents more than that patients with fibrous crescents. (14) Sharma et. al. they documented that $64 \%$ of patients on a study of 22 patients 14 out of them by histopathological renal biopsy a high incidence of advanced renal failure related to higher chronicity changes specially if the majority of patients were affected by fibro-cellular crescents and $45 \% 10$ out of 22 patients reported glomerular sclerosis at time of presentations . (7) Southwest Pediatric Nephrology 
Study Group on 50 children reported that $37 \%$ of the glomerular crescents were cellular and $63 \%$ of glomerular crescents were fibro-cellular or fibrous .

\section{CONCLUSION}

$80 \%$ of children suffering from post-streptococcal glomerulonephritis regained normal blood pressure , also their renal functions became normal in limited our twenty patients with post-streptococcal crescentic glomerulonephritis and their very good prognosis due to the effect of immunosuppressive therapy .

\section{ACKNOWLEDGEMENT}

Members of nephrology unit of Zagazig general and Health Insurance hospitals in Sharkia

\section{REFERENCES}

1- Palmer A, Villips J, Baliga R. Glomerulonephritis associated with acute pneumococcal pneumonia: a case report. Pediatr Nephrol 2005 20(10):1494-1495

2. Porcella SF, Beres SB, Sesso R, Pinto SWL, Hoe NP, DeLeo FR, Musser JM .Genome sequence of a lancefield group C Streptococcus zooepidermicus strain causing epidemic nephritis: new information about an old disease. PLoS One 2008 21(3):e3026

3. Steer AC, Danchin MH, Carapetis JR. Group A streptococcal infections in children. J Paediatr Child Health 2007 43(4):203-213

4- Rodriguez-Iturbe,B,Musser,JM.The current state of poststreptococcal glomerulonephritis. J Am Soc Nephrol; 2008 19:1855

5- Morris MC, Wong W, Zwi J. Outcome of severe acute post-streptococcal glomerulonephritis in New Zealand children. Pediatr Nephrol. 2009;24(5):1021-

6- Sobin LH ,Chaerge . Renal disease:classification and atlas of glomerular disease.

In: World Health Organization (WHO) (ed) Monograph1981,New York, Igaku-Shoin Medical Publishers, Tokyo, pp 3-9

7- Southwest Pediatric Nephrology Study Group .A clinico-pathologic study of crescentic glomerulonephritis in 50 children. A report by the Southwest Pediatric Nephrology Study Group. Kidney Int 1985 27:450-458

8- Risdon A, Jardim HMPF, Leake J, Barratt TM, Dillon MJ.Crescentic glomerulonephritis in children.Pediatr Nephrol 1992;6:231-235

9- Sulyok A . Acute proliferative glomerulonephritis.In Avner, E D.; Harmon, W E.; Niaudet, P,(eds):Pediatric nephrology, $5^{\text {th }}$ ed ,Philadelphia,2004 Lippincott Williams \& Wilkins:601-13.

10- Kohler PF, Ten Bensel R (1969) Serial complement component alterations in acute glomerulonephritis and systemic lupus erythematosus. Clin Exp Immunol 4:191-202PubMedGoogle ScholarW, Eiam-Ong, SAn update on acute postinfectious glomerulonephritis worldwide. Nat Rev Nephrol; 2009 5:259

11. Lavjay Butani. Prolonged hypocomplementaemia after post-streptococcal glomerulonephritis. Nephrol Dial Transplant 2001 16: 869,

12- Pinto, SW, Sesso, R, Vasconcelos, E. Follow-up of patients with epidemic poststreptococcal glomerulonephritis. Am J Kidney Dis; 2001 38:2

13- El-Agroudy A.E., El-Husseini A.A., Moustafa F.E.,M.A., Fouda M.A.\& Sobh M.A. Impact of clinical and histopathological factors on outcome of Egyptianpatients with crescentic glomerulonephritis.International Urology and Nephrology 2003 35: 543-551.

14- Sharma R, Dewan D, Prasad N, JainM, Gupta A and Kumar A. Clinical spectrum and outcome of crescentic glomerulonephritis in children in developing countries. Pediatr Nephrol 2008 23:389-394

15- Vasudev AS, Srivastava RN, Moudgil A, Bagga A, Bhuyan UN, Sundraem KR . Crescentic glomerulonephritis 
in children: a review of 43 cases. Am J Nephrol 1992 12:155-161

16- Steele BT ,Miller MN, Baumal R, Poucell S. Incidence and prognostic importance of glomerular crescents in renal disease of childhood. Am J Nephrol 1984 4:244-247

17- Murphy WM, Roy S 3rd, Arant BS Jr . Poststreptococcal crescenteric glomerulonephritis in children: comparison of quintuple therapy versus supportive care. J Pediatr 1981 98:403-41

18- Herdson PB, Lewy JE, Salinas-Madrigal L, Pirani CL, Metcoff J . Clinico-pathologic correlations in acute poststreptococcal glomerulonephritis. A correlation between renal functions, morphologic damage and clinical course of 46 children with acute poststreptococcal glomerulonephritis. Medicine (Baltimore) 1971 50:453-501

19- Stollerman GH (1971) Rheumatogenic and nephritogenic streptococci. Circulation 43:915921PubMedGoogle Scholar

20- Fuentes F, Morales R, Martinez J , Mompean EO Acute post-estreptoccocal glomerulonephritis in the elderly Nefrologia 2008 28(1):113-114 | Doi

21- Hebert T, Raouff A, Pullma J, Coco M. Crescentic post streptococcal glomerulonephritis with nephrotic syndrome in an adult: is aggressive therapy warranted. Clin Nephrol 2005 63:375-380

22- Sabry A.A., Sheashaa H.A., Moustafa F.E.,\&SobhM.A.Acutepostinfectiouscrescentic glomerulonephritis:Clinicopathologic presentation and risk factors.International Urology and Nephrology 2005 37:603-609

23- Kerr PG, Atkins RC, Lan HY.Rapidly progressive glomerulonephritis.In: Schrier RW, Gottschalk CW,eds. Diseases of the Kidney 1997.Boston: Little, Brown,; 1617-1644.

24-Dillon HC Jr (1967) Pyoderma and nephritis. Annu Rev Med 18:207-218PubMedGoogle Scholar

25- Moore MS, Updyke EL, Conroy E (1955) Provisional new type of group A streptococci associated with nephritis. Science 121:171-172PubMedGoogle Scholar 